Please do not remove this page

RMIT

UNIVERSITY

\title{
Compressive behavior of luffa sponge material at high strain rate
}

Shen, Jianhu; Xie, Yimin; Huang, Xiaodong; Zhou, Shiwei; Ruan, Dong

https://researchrepository.rmit.edu.au/esploro/outputs/9921859484601341/filesAndLinks?institution=61RMIT_INST\&index=null

Shen, J., Xie, Y., Huang, X., Zhou, S., \& Ruan, D. (2013). Compressive behavior of luffa sponge material at high strain rate. Key Engineering Materials, 535-536, 465-468.

https://doi.org/10.4028/www.scientific.net/KEM.535-536.465

Published Version: https://doi.org/10.4028/www.scientific.net/KEM.535-536.465

Repository homepage: https://researchrepository.rmit.edu.au

(C) (2013) Trans Tech Publications, Switzerland

Downloaded On 2023/04/26 22:09:49 +1000

Please do not remove this page 
Thank you for downloading this document from the RMIT Research Repository.

The RMIT Research Repository is an open access database showcasing the research outputs of RMIT University researchers.

RMIT Research Repository: http://researchbank.rmit.edu.au/

\section{Citation:}

Shen, J, Xie, Y, Huang, X, Zhou, S and Ruan, D 2013, 'Compressive behavior of luffa sponge material at high strain rate', Key Engineering Materials, vol. 535536, pp. 465-468.

See this record in the RMIT Research Repository at:

http://researchbank.rmit.edu.au/view/rmit:19990

Version: Accepted Manuscript

Copyright Statement: (c) (2013) Trans Tech Publications, Switzerland

Link to Published Version:

http://dx.doi.org/10.4028/www.scientific.net/KEM.535-536.465 


\title{
Compressive Behavior of Luffa Sponge Material at High Strain Rate
}

\author{
Jianhu Shen ${ }^{1, a}$, Yi Min Xie ${ }^{1, b}$ Xiaodong Huang ${ }^{1, c}$, Shi Wei Zhou ${ }^{1, d}$, and Dong \\ Ruan ${ }^{2, \mathrm{e}}$ \\ ${ }^{1}$ Innovative Structures Group, School of Civil, Environmental and Chemical Engineering, RMIT \\ University, GPO Box 2476, Melbourne 3001, Australia \\ ${ }^{2}$ Faculty of Engineering and Industrial Sciences, Swinburne University of Technology, John Street, \\ Hawthorn, VIC 3122, Australia \\ ajianhu.shen@rmit.edu.au(corresponding author), ${ }^{b}$ mike.xie@rmit.edu.au, \\ chuang.xiaodong@rmit.edu.au, ${ }^{\mathrm{d}}$ shiwei.zhou@rmit, ${ }^{\mathrm{e}} \mathrm{druan@groupwise.swin.edu.au}$
}

Keywords: Luffa sponge, mechanical properties, energy absorption, strain rate.

\begin{abstract}
The strain rate effect of luffa sponge material is an indispensable property for it to be used for acoustic, vibration, and impact energy absorption. Compressive tests at different strain rates on cylindrical column specimens of luffa sponge material were conducted over a wide density ranging from 24 to $64 \mathrm{~kg} / \mathrm{m}^{3}$. A photographic technique was applied to measure the section area of the specimen with irregular shape. The mechanical properties of luffa sponge material at various strain rates were obtained based on this measurement. The dynamic data were compared to those of quasi-static experiments. It was found that compressive strength, plateau stress and specific energy absorption of luffa sponge material were sensitive to the rate of loading. Empirical formulae were developed for strength, densification strain and specific energy absorption at various strain rates in the macroscopic level by considering the luffa fiber as base material.
\end{abstract}

\section{Introduction}

Cellular materials are commonly used as packaging and cladding materials to protect products and personal during collision and impact events [1,2]. The mechanical characterization of those cellular materials at varying strain rates is essential for their efficient use at dynamic loading applications. As we approach the limit of non-renewable natural resources, there is an increasingly urgent need to find alternative materials that fulfill not only the mechanical stability but also some integrated multi-functional properties with low environmental impact and renewable source of reproduction [3]. The fruits of Luffa Cylindrical (LC) have a netting-like fibrous vascular system. When they are dried, the fibrous network structure serves like an open cell foam material. It is proved to be one of those commercial viable and environmental acceptable biological cellular materials in our previous research. It is derived from fruit of luffa cylindrical plant and having recycling capability and triggered biodegradability $[4,5]$. Due to the high strength-to-weight ratio of cellular materials, it can be used as good packaging material, impact resistance and excellent energy dissipation materials. The importance of luffa sponge is growing in our society because of the search for sustainable solutions for new materials.

Only a limited amount of research has been conducted on the luffa sponge as a source of biofibres and bio-composites in the last ten years. Those researches indicated that it is a potential alternative material for water absorption, and waste water treatment. The luffa fibers were also used as reinforcement fibre for other materials [6-8] and cell immobilization for biotechnology. However, there is a lack of scientific data on the mechanical properties of luffa sponge material because up to now its main practical use has been as a body scrub in the bathroom. Due to the lack of experimental proofs, their complex hierarchy microstructures and other common limitations of biological materials, potential applications have not been applied in practice for luffa sponge material as well as luffa fibres. No experimental investigation was conducted on its dynamic 
properties. At the same time, sponge gourd (L. cylindrica), the origin of luffa foam material, have not yet had their potentialities fully explored.

To this end, the dynamic mechanical properties of luffa sponge columns were tested and compared with other cellular materials to check the performance of this light weight material. Uniaxial dynamic compressive tests were conducted at a strain rate of $10^{0}$ and $10^{2} \mathrm{~s}^{-1}$ by using a High Rate Instron machine to study the energy absorption of luffa sponge material. Cylindrical specimens with different relative density were tested at a room temperature of $22^{\circ} \mathrm{C}$ and a humidity of around $40 \%$. An energy efficiency method was adopted to obtain the values of the densification strain and plateau stress, and thus the energy absorption capacity per unit volume. The experimental results are also discussed together with quasi-static data in our previous research [9].

\section{Experiments}

Specimens. According to the standard of compressive tests and recent research [10] on other cellular material, the specimen size effect is negligible for foams when the dimension of specimen is sufficiently larger than the cell size, i.e., 7 times of the cell size for metallic foams. Thus the specimen for luffa sponge should be large enough to eliminate the specimen size effect. A typical specimen is shown in Fig. 1. The available maximum size along radial direction for luffa sponge is whole section of the luffa sponge column. It will be used as the cross section of the specimen which is range from $55 \mathrm{~mm}$ to $86 \mathrm{~mm}$ in diameter. The height of the specimen was selected as around $50 \mathrm{~mm}$ in our test. A bandsaw cutting machine was used to cut the specimen from an initial dried luffa bath sponge. After the initial cutting, the specimens were milled further to make the two cutting surface smooth and parallel. For most of the specimens, the section area at two ends of the specimen is different, thus besides the specimen, two thin slices (about $5 \mathrm{~mm}$ thick) were cut from the two ends of the luffa sponge to be used as samples to measure the cross section area of luffa sponge specimen. Because the cross section for most of the specimens is not perfect circular, a photograph for each slice was taken and Photoshop was used to get the area of the cross section. Then the section area of the specimen is the average value of these two slices. The volume of the luffa sponge specimen is the product of this cross section area and the height of the specimen.
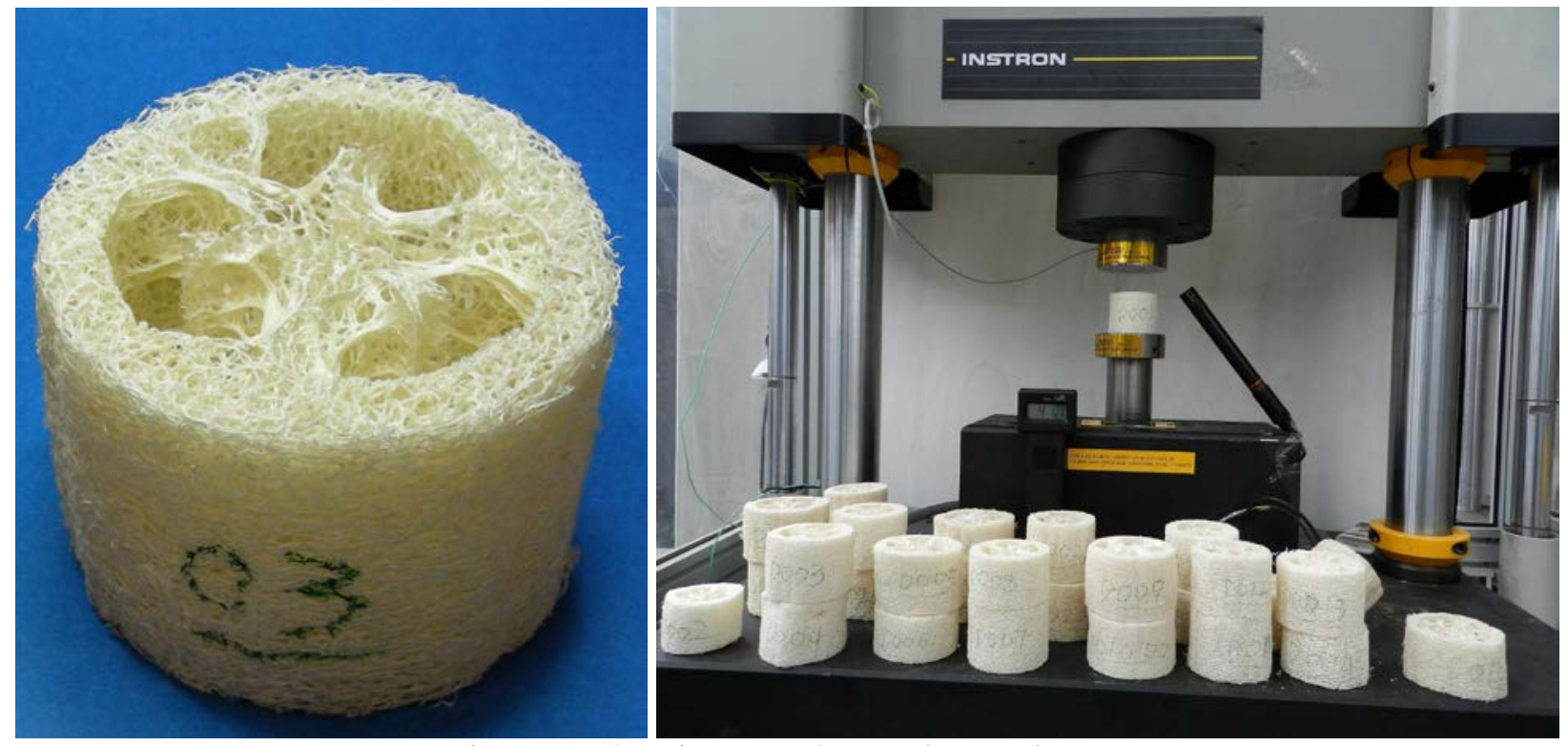

Figure 1: Specimen and experimental setup

Test Equipment and Settings. Dynamic uni-axial compressive tests were conducted at two strain rates, namely, 1 and $10^{2}$, to obtain the foam properties under dynamic loading with different strain rate. For each strain rate, about 30 specimens were tested with densities ranging from 24 to 64 $\mathrm{kg} / \mathrm{m}^{3}$. All the tests were performed at a room temperature of $22^{\circ} \mathrm{C}$ and humidity around $40 \%$.

The dynamic tests were performed using a High Rate Instron Test System with two different drive methods. A low rate method was selected for strain rate around $1 \mathrm{~s}^{-1}$ and a high rate method 
with drive profile was adopted for the other strain rate, i.e. $10^{2} \mathrm{~s}^{-1}$. A photograph of the dynamic experimental setup is shown in Fig. 1. The specimen was placed on the bottom compression platen which was positioned at a considerable long distance from the top platen as the beginning of each test. The specimen was accelerated to the required velocity across that distance before the top surface of the specimen touches the top platen. Double sided tape was used to retain the specimen on the bottom platen and avoid any possible slip of the specimen.

A constant speed of $5.0 \mathrm{~m} / \mathrm{s}$ with a sampling rate of $500 \mathrm{kHz}$ for dynamic compression tests at a strain rate of $10^{2} \mathrm{~s}^{-1}$. The load history was measured by Kistler load cell 9071A without data filter. The displacement history was measured by an inherent LVDT with data filter by setting cut off frequency of $1000 \mathrm{~Hz}$. The humidity during the test was monitored as shown in Fig. 1 . The specimens were placed in the test room for at least 2 hours before the compressive test to eliminate the difference in temperature and humidity. The temperature in the test room was from $20^{\circ}$ to $28^{\circ}$, but during each test its variation was less $1^{\circ}$. The humidity was between $30 \%$ and $46 \%$, but during each test its variation was less $1.0 \%$.

\section{Experimental Results}

Deformation Features. Force and displacement histories were obtained by the Instron machine (VHS 8800). It shows clearly a fairly constant compressive force over a long stroke, which represents an ideal energy absorption feature. Nominal stress (defined as force over original cross sectional area) and nominal strain (defined as displacement over original height of the foam specimen) were calculated. The overall compression strain of the specimen is axial along longitudinal direction rather than folding of the wall of the specimen. Similar to other cellular materials, the compressive deformation process for luffa sponge material under dynamic loading was not uniform. Localized crushing band was observed which is similar to the quasi-static compression behavior of luffa sponge material.

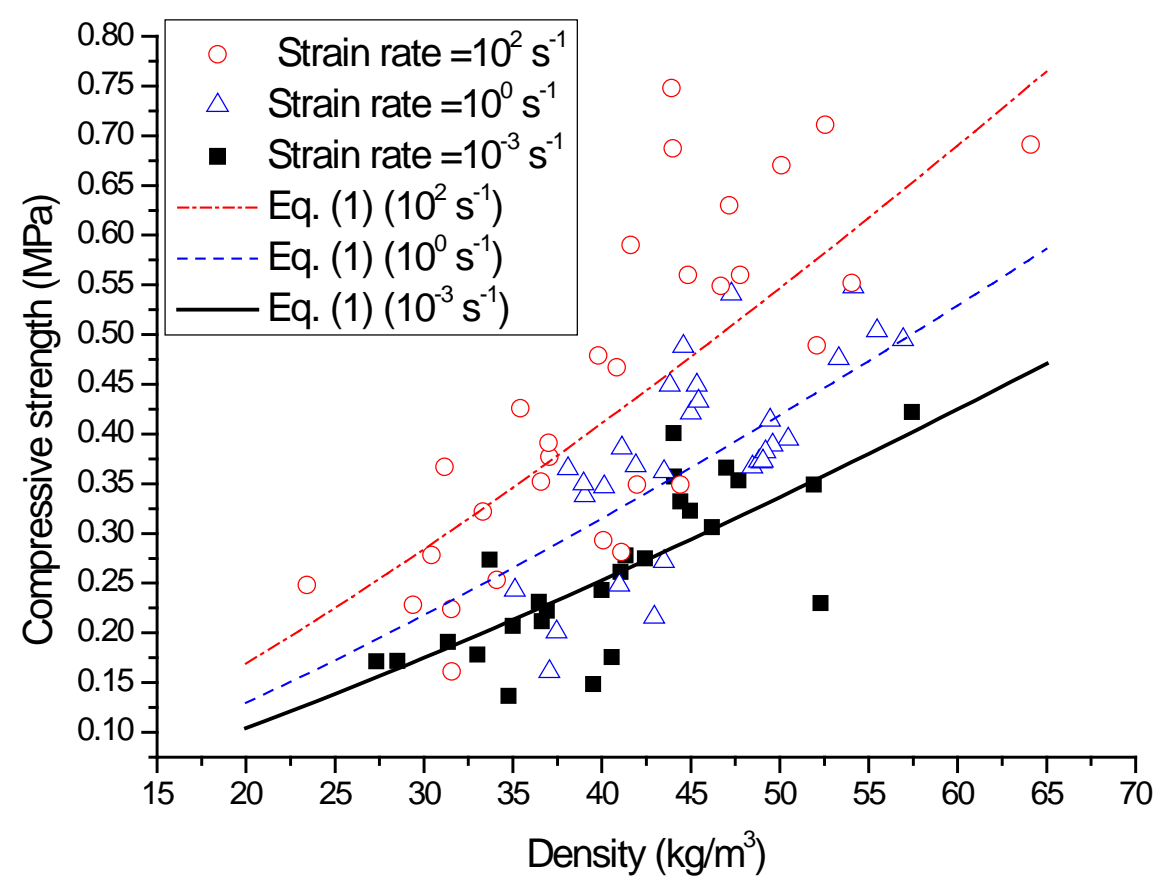

Figure 2: Compressive strength at various strain rates.

Strain Rate Effect. Similar to other cellular materials [1], the compressive strength of the luffa sponge material is taken to be the initial peak stress if it exists. If there is no such peak stress, the stress at the intersection of two slopes is taken to be the compressive strength, namely, the slope for the initial loading and that for the stress plateau. The compressive strength at various strain rates is shown in Fig. 2. It can be seen clearly that the compressive strength increases with the strain rate 
despite the scattering of the experimental data. Similar trend was found for plateau stress and specific energy absorption. The densification decreases slightly with the increasing strain rate which can be neglected for simplicity.

Empirical Formula. For a traditional rate sensitive material, the strain rate effect is independent on the density of the material. Thus formula with two power-law items was used for the compressive strength, plateau stress, and energy absorption. The luffa fiber was used as base material for the luffa sponge column in our experiment. By fitting to a power law relationship using the quasi-static data in our experiment together with the relevant data $\left(\rho_{f}=0.353 \mathrm{~g} / \mathrm{cm} 3, \sigma_{f}=11.1\right.$ $\mathrm{MPa}$ ) from literature for the similar luffa fiber [6], the coefficient and power are 0.37 and 1.28, respectively. The item for strain rate was simply solved by using the three different sets of experimental data. The empirical formula for compressive strength is presented in Eq. 1.

$$
\frac{\sigma_{0}}{\sigma_{f}}=0.37(1+0.24 \varepsilon)\left(\frac{\rho_{0}}{\rho_{f}}\right)^{0.28}
$$

where $\sigma_{0}$ and $\rho_{0}$ are the compressive strength and density for luffa sponge, $\sigma_{f}$ and $\rho_{f}$ are the strength and density for luffa fibres. The empirical prediction is shown in Fig. 2. It can be seen that the prediction of Eq. 1 agrees well with the experimental data.

\section{Summary}

Compressive tests at different strain rates on cylindrical column specimens of luffa sponge material were conducted over a wide density ranging from 24 to $64 \mathrm{~kg} / \mathrm{m}^{3}$. The dynamic data were compared to those from quasi-static experiments. It is found that compressive strength, plateau stress and specific energy absorption of luffa sponge material are sensitive to the rate of loading. Empirical formulae were developed for strength, densification strain and specific energy absorption at various strain rates in the macroscopic level by considering the luffa fiber as base material.

\section{References}

[1] L.J. Gibson, M.F. Ashby, B.A. Harley, Cellular materials in nature and medicine, Cambridge University Press, Cambridge, 2010.

[2] G. Lu, T.X. Yu, Energy absorption of structures and materials, Woodhead Publishing Ltd, Cambridge, 2003.

[3] H.P.S.A. Khalil, A.H. Bhat, A.F.I. Yusra, Green composites from sustainable cellulose nanofibrils: A review, Carbohydr. Polym. 87 (2012) 963-979.

[4] I.O. Oboh, E.O. Aluyor, Luffa cylindrica - an emerging cash crop, African J. Agr. Res. 4 (2009) 684-688.

[5] M.J. John, S. Thomas, Biofibres and biocomposites, Carbohydr. Polym. 71 (2008) 343-364.

[6] M.A. Paglicawan, M.S. Cabillon, R.P. Cerbito, E.O. Santos, Loofah fiber as reinforcement material for composite, Philipp. J. Sci. 134 (2005) 113-120.

[7] L. Ghali, S. Msahli, M. Zidi, F. Sakli, Effect of pre-treatment of Luffa fibres on the structural properties, Mater. Lett. 63 (2009) 61-63.

[8] E. Laranjeira, L.H.d. Carvalho, S.M.d.L. Silva, J.R.M. D’Almeida, Influence of fiber orientation on the mechanical properties of polyester/jute composites, J. Reinf. Plast. Compos. 25 (2006) 1269-1278.

[9] J. Shen, Y.M. Xie, X. Huang, S. Zhou, Accepted by Journal of Mechanical Behavior of Biomedical Materials (2012).

[10] M.I. Idris, T. Vodenitcharova, M. Hoffman, Mechanical behaviour and energy absorption of closed-cell aluminium foam panels in uniaxial compression, Mater. Sci. Eng. A 517 (2009) 37-45. 